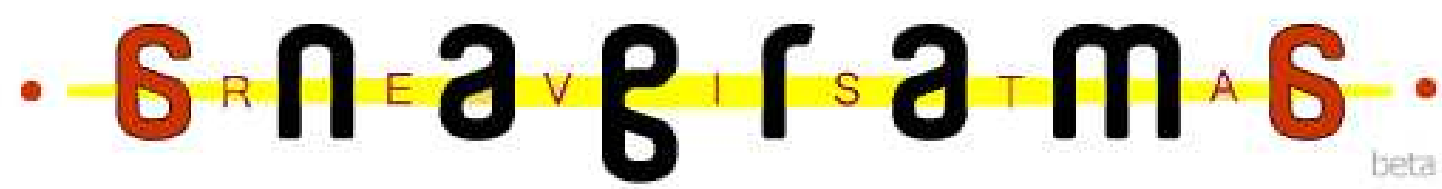

\section{Para identificar e relembrar Sophie Calle: o papel da fotografia e do terto ao construir memórias}

Amanda Savioli Marques Tauares*

\section{Resumo}

Este artigo tem como objetivo analisar o conjunto da obra da artista conceitual francesa Sophie Calle, sob o viés da construção de memórias através da fotografia, do texto e da combinação entre eles. Pretende-se discutir o contexto em que seus projetos foram produzidos e seus efeitos no público-leitor, bem como apontar os processos de memória e identificação realizados por Calle nos âmbitos pessoal e coletivo.

Palauras-chaue: fotografia; discurso; memória; autobiografia; Sophie Calle.

Assim como a fotografia e a palavra, a memória é, ao mesmo tempo, ligada à documentação e à criação, ao real e ao imaginário. Ela depende das situações, dos lugares, de quem as assimila, de quem tenta alterá-las, de quem as expressa, do tempo passado, do presente e até das projeções para o futuro. Para Jacques Le Goff (1996, p. 424), as atuais teorias sobre ocorrências da memória corroboram a tese de que, "tanto nos seus aspectos biológicos como nos psicológicos, [os fenômenos da memória] mais não são do que resultados de sistemas dinâmicos de organização e apenas existem na medida em que a organização os mantém ou os reconstitui”.

Apesar de ser muito associada ao caráter individual, "a memória deve ser entendida também, ou sobretudo, como um fenômeno coletivo e social, ou seja, como um fenômeno construído coletivamente e submetido a flutuações, transformações, mudanças constantes"

\footnotetext{
* Graduanda em Comunicação Social: Jornalismo pela Universidade Estadual Paulista (UNESP). Foi bolsista $\mathrm{CNPq}$ pelo programa Ciência sem Fronteiras para graduação sanduíche na University of Roehampton (Londres, Inglaterra). Atualmente, desenvolve pesquisa de iniciação científica financiada pela FAPESP, sob orientação da Prof. ${ }^{\text {a Dr. }}{ }^{a}$ Eliza Bachega Casadei.
} 
(POLLAK, 1992, p. 201). Uma não pode existir sem a outra: a memória coletiva, por exemplo, depende dos detalhes, dos pequenos relatos, dos personagens para ser criada; por outro lado, a memória individual é, sem dúvidas, influenciada pelos contextos políticos, econômicos, culturais, sociais e, obviamente, históricos dos grupos em que estamos inseridos.

Uma das mais importantes funções da memória é a constituição da identidade, seja ela individual ou coletiva. De acordo com Michael Pollak (1992, p. 204), a memória é "um fator extremamente importante do sentimento de continuidade e de coerência de uma pessoa ou de um grupo em sua reconstrução de si”. É ela a responsável por fornecer referências e por delimitar as fronteiras sociais e ideológicas que ditarão o comportamento individual ou coletivo em determinadas situações, repetidas ou não. Nesse caso, embora ainda dependente de alguns poucos fatores "internos", a memória passa a ser essencialmente social por depender da comparação.

"Se a memória é socialmente construída, é óbvio que toda documentação também o é” (POLLAK, 1992, p. 207). Apesar disso, é somente através das representações, dos signos, que se pode construir um patrimônio da memória e justificá-la. Neste artigo, pretende-se analisar a maneira como a artista francesa Sophie Calle articula diversos elementos gráficos, fotográficos e textuais para conceber processos de memória e identificação nos âmbitos pessoal e coletivo. É interessante também destacar os resultados desses recursos no conjunto de sua obra, seja comparando-a a outras e identificando suas tendências discursivas, seja analisando seus efeitos no público-leitor.

\section{Identificando Sophie Calle}

Sophie Calle nasceu em Paris, em 9 de Outubro de 1953. Filha de um famoso médico oncologista francês que colecionava pop art e de uma mãe que trabalhava como assessora de imprensa, ela nunca formou-se oficialmente em nada relacionado à arte: suas influências vieram da família e, em seguida, de suas próprias experiências cotidianas. Ao terminar a escola, Calle viajou pelo mundo por sete anos; foi ao retornar a Paris que ela iniciou seus trabalhos na fotografia. Suas primeiras imagens são de cemitérios e pessoas desconhecidas que ela seguiu passeando pelas ruas, como uma forma de re-conhecer a cidade e seu povo e lidar com seus próprios sentimentos de isolamento e desnorteamento. 
$\mathrm{Na}$ época, Calle desenvolveu dois projetos distintos que se tornaram famosos: Les Dormeurs e Suite Venetienne. O primeiro consiste na documentação fotográfica e textual de encontros de Calle com amigos, vizinhos e desconhecidos numa situação bastante inusitada. Durante uma semana inteira, a artista recebeu essas pessoas em sua própria cama, em intervalos de 8 horas. Cada um dos personagens recebia café da manhã e lençóis limpos e, em troca, deveria permitir que a autora lhes fizesse perguntas variadas e os fotografasse enquanto dormiam. Já o segundo trabalho, publicado em formato de livro/diário, é resultado do voyeurismo da francesa ao retornar à sua cidade natal. Ao ser apresentada a um homem que ela havia seguido em Paris, descobre que o mesmo tem uma viagem programada a Veneza. A artista decide, então, segui-lo disfarçadamente numa jornada de 13 dias, fotografando-o sempre que possível e misturando fatos e pensamentos em sua narrativa.

Ambas as obras demonstram o interesse de Sophie Calle em explorar as questões que envolvem o íntimo e o público, bem como de relatar a vida das outras pessoas sob uma perspectiva própria e, é claro, pessoal. Embora ela afirme que, inicialmente, esses projetos não tenham sido concebidos como arte conceitual, foram eles que impulsionaram sua carreira como artista: em 1980, Calle é convidada para realizar sua primeira exposição, na Biennale des Jeunes do Museu de Arte Moderna de Paris. A partir de então, a francesa passa a trabalhar com fotografias, vídeos, textos e performances a fim de ressignificar, de maneira criativa, a relação entre esses suportes e entre os temas que escolhe - ficção e realidade, presença e ausência, identidades e aparências, vulnerabilidade.

Há controvérsias em relação a qual dessas suas duas obras foi elaborada primeiro. Conforme explica Batton (2011) em um ensaio sobre o conceito da ilustração fotográfica em Suite Venetienne, é provável que esse projeto tenha sido desenvolvido em partes: inicialmente, em 1979, ao seguir o homem por Veneza, Calle realiza uma documentação dos fatos; no ano seguinte, recria as mesmas situações com atores por motivos legais de exposição de seu sujeito-objeto. O autor aponta que o entrelaçamento entre os dois 'sets' de fotografias na narrativa é tão sutil que o público mal consegue separar os acontecimentos originais das ações performáticas, salientando o caráter engenhoso e até desleal da obra. Isso também acontece com a parte textual do livro, que foi aparentemente reescrita para que, de certa forma, consiga ilustrar o que é contado através das imagens. Calle tenta despistar não somente seu perseguido, mas também seu leitor, ao se retratar 
como uma detetive descuidada que, na verdade, calcula minuciosamente cada inserção no relato.

Essa condição enigmática permeia todas as produções de Sophie Calle. É particularmente interessante analisar suas abordagens de relação texto-imagem, ao passo que ela se apropria do conceito de ilustração de maneira bastante criativa. No caso de Suite Venetienne, por exemplo, ao recriar fotografias tiradas por seu sujeito-objeto, ou ao reconstituir cenas que já havia documentado, a artista consegue remover o caráter documental de suas fotografias-ilustração e situá-las como imagens conceituais dentro de sua história (BATTON, 2011). Elas passam a ressignificar o texto de maneira dúbia, ao mesmo tempo em que assumem múltiplos significados por causa dele. Assim, é possível afirmar que toda a parte documental do projeto pode - e talvez até deva - ser percebida como uma performance. Calle ressignifica sua própria identidade com seus disfarces, mas também ao se tornar escrava de uma perseguição ao mesmo tempo superficial e determinante para o projeto.

Esse uso de restrições arbritárias, impostas pela própria autora, evoca as influências do movimento literário Oulipo (Ouvroir de Litterature Potentielle) nas obras de Calle. Estabelecido na década de 1960 por escritores e matemáticos franceses, o grupo tentava utilizar a criação de padrões e técnicas bem definidos para despertar novas ideias e criar trabalhos lúdicos e divertidos. Nas composições da francesa, as normas aparentemente banais - e às vezes um pouco absurdas - tornam-se o fio condutor de suas narrativas $\mathrm{e}$ conduzem o leitor por uma experiência organizada, ao mesmo tempo em que inserem toques de humor e de subjetividade aos trabalhos. Essas tendências podem ser claramente percebidas, por exemplo, em Doubles Jeux, projeto em que Calle mistura suas próprias elaborações à produção do amigo e escritor Paul Auster.

Double Jeux (1998) é uma coletânea de 7 outros livros - De L'obéissance, Le Rituel D'anniversaire, Les Panoplies, A suivre, L'hôtel, Le Carnet D'adresses e Gotham Handbook. Seguindo a mesma estrutura, cada um deles se relaciona, como o nome do livro organizador sugere, num jogo duplo com a obra Leviatã (2001), de Paul Auster, apresentando, inclusive, um trecho de referência. Em Leviatã, a personagem Maria Turner - também artista, escritora e fotógrafa - apresenta comportamentos e ações baseados em trabalhos já realizados por Calle; em Double Jeux, Calle se apropria de alguns elementos da narrativa ficcional do amigo para realizar seus novos trabalhos. 
Assim, em De L'obéissance, por exemplo, Calle troca de lugar com Maria e segue à risca rituais impostos por Auster à sua personagem: ela acompanha uma dieta cromática para cada dia da semana, além de viver dias inteiros baseados em uma única letra do alfabeto. Já Gotham Handbook é baseado num manual criado por Auster para que Sophie Calle se comporte bem em Nova Iorque: ele lhe dá recomendações sobre diversas ações e pede-lhe que sejam realizadas em um espaço público. A francesa, então, escolhe uma cabine telefônica como seu espaço de ação e passa a contabilizar suas experiências num relatório e em fotos. Em Le Ritual D’anniversaire, Calle segue um outro ritual, referenciado inclusive por outro autor que não Auster. Desta vez, registra os presentes de aniversário que ganha durante 13 anos, em festas organizadas por ela mesma, cujo número de convidados corresponde à sua idade recém-completada e inclui sempre um desconhecido.

Les Panoplies, talvez a narrativa mais sensual na obra de Calle, é dividido em dois grandes episódios: no primeiro, ela conhece um homem cujo estilo não lhe agrada e passa a enviar para ele, todos os Natais, uma peça de roupa; no segundo, a autora coloca uma peruca loira e vai a Pigalle realizar um strip-tease numa tenda de um parque de diversões. A suivre é uma versão adaptada do já discutido Suite Venétienne, enquanto L'hôtel traz narrativas imaginadas por Calle sobre hóspedes do hotel onde trabalhou como camareira; os comentários são baseados em fotografias dos objetos que eles descuidadosamente deixaram ali.

Por fim, em Le Carnet D'adresses, Sophie Calle encontra uma agenda de telefones na rua e passa a telefonar a todos os contatos registrados, a fim de criar uma imagem do dono. Ela devolve o caderno, mas suas anotações e depoimentos são publicados no jornal Libération durante quase dois meses em 1983. O dono da caderneta, Pierre D., escreve ao jornal criticando a publicação e pedindo seu direito de resposta; alguns dias depois, uma fotografia da jovem Calle, nua e com as feições disfarçadas, é também veiculada. O projeto rendeu à autora uma ameaça de processo legal e ela concordou em não difundir a obra até que Pierre estivesse morto. É por isso que, na edição inicial de Double Jeux, somente a página inicial e final do projeto estão inclusas. Em entrevistas e no próprio texto de $L e$ Carnet D'adresses, Calle afirma que havia ido longe demais com a proposta; de fato, as críticas gerais a este trabalho se dão devido ao formato de verdades factuais que ele assumiu com a publicação no jornal parisiense (O’NEILL-BUTLER, 2012). 


\section{Relembrando Sophie Calle}

O trabalho de Calle também acompanha tendências bastante recentes para autobiografias e autoficções na França, embora a artista não produza somente esse gênero. Nessa área da literatura, o crescente aumento de componentes visuais - em especial de fotografias - passou a incentivar a interpretação desse tipo de obra como um processo (e não como produto), além de potencializar rupturas nas narrativas lineares. Conforme explicam Edwards, Hubbell e Miller (2011, p. 01), essas "fotografias, mostradas ou retidas, caracterizaram as narrativas pessoais, sendo oferecidas como evidência ou como metáfora daquilo que foi, daquilo que poderia ter sido, ou do que não pode ser dito". Dessa forma, a estruturação dessas histórias passou a adotar múltiplos e diversos significados subjetivos, além de estimular debates sobre a falta de autenticidade - intencional ou não - desses relatos.

Assim, nessas obras, ocorre um processo de relativização do referencial narrativo. Os autores, ao assumirem a impossibilidade da imparcialidade total em seus relatos, que são geralmente afetivos, quebram o antigo pacto de verdade absoluta entre leitor e escritor nas autobiografias. Essa noção também é transferida para as fotografias, o que resulta em novas maneiras de articulação entre texto e imagem. Com essas mudanças, esses elementos "não se encontram mais numa relação de referencialidade (identificar, nomear, descrever, contemplar, reconstruir), mas sugerem lacunas, tensões e até mesmo conflitos entre si” (MONTÉMONT, 2011, p. 39). É com base nessas subjetividades que o leitor passa a interpretar as autobiografias, misturando fatores documentais aos criativos. O resultado são milhares de possíveis narrativas - entre elas, a inicialmente sugerida pelo autor, as finalmente imaginadas por cada leitor e até mesmo aquelas que passam despercebidas para os dois.

Em contrapartida, é importante ressaltar que a associação efetiva entre autobiografia e fotografia só é possível devido a esse senso de indeterminação criado por sua relação. Nenhum pode funcionar como garantia de veracidade do outro; ao contrário, geralmente intensificam a complexidade e ambiguidade compartilhadas por esses elementos separadamente (EDWARDS, HUBBELL, MILLER, 2011, p. 08). Essa similaridade também pode ser observada no caráter íntimo evocado pelos dois suportes. $\mathrm{O}$ texto autobiográfico, em sua origem, pressupõe o compartilhamento de informações e 
pontos de vista que só poderiam ser atingidos pelo próprio sujeito ou por aqueles que são muito próximos dele. A incorporação da fotografia nessas narrativas, ao explorar o potencial de relatar ao mostrar fisicamente, reforça os sentimentos ambíguos de excitação e ansiedade do leitor em relação a essa aproximação real (JORDAN, 2011, p. 53).

Assim, esses resultados da combinação entre texto biográfico e fotografia seriam as chamadas fotobiografias - termo cunhado em 1983 através do Manifeste Photobiographique, escrito por Gilles Nora e Claude Nori. A proposta do grupo de artistas e teóricos era de relacionar intimamente fotografia à vida, criando premissas para uma nova linguagem visual. Montémont (2011, p. 31) define o gênero como "nem uma categoria genérica, nem a adição mecânica de dois discursos, mas um sistema composto que possui três aspectos: textual, icônico, e as relações explícitas ou implícitas entre os dois". A autora explica a mediação de realidades realizada por esses dois elementos como complementar, complexa e invertida: enquanto o texto oferece uma realidade em signos que é posteriormente reconstruída e interpretada, a fotografia oferece uma realidade visual para que, em seguida, seja possível decodificar o seu referente. Também é importante destacar que, no âmbito da fotobiografia, não se subordina imagem à texto, ou vice-versa; ambos podem ser interpretados separadamente, mas é no jogo entre eles que a obra se torna interessante e viva.

Neste caso da incorporação da fotografia à autobiografia, discute-se que o maior desafio é estabelecer sentido e contexto através de um suporte essencialmente fragmentário. Para alguns teóricos da área, isso seria possível somente através da relação com a linguagem, que possui sistemas como o pronominal para consolidar o caráter enunciativo e introspectivo dos projetos. Enquanto na autobiografia é impossível separar autor de narrador, na fotografia isso se torna até necessário, pois ela não é capaz de identificar o "eu" sem utilizar recursos linguísticos - são os dilemas dos auto-retratos, por exemplo, nos quais o fotografado precisa se declarar também como fotógrafo; ou dos retratos de infância, frequentemente adicionados às narrativas, embora inicialmente elaborados sob pontos de vista que não o do protagonista.

Apesar disso, a fotografia se torna um instrumento relevante de enunciação na autobiografia porque ela é vista como parte do "eu" enunciador; o determinante não é somente o seu conteúdo, mas o seu papel como símbolo ou memória daquilo que é efetivamente dito. De acordo com Montémont (2011, p. 45), "as fotografias posam, em última análise, o problema da compreensão que os indivíduos tem de sua própria memória, 
sua habilidade de pensar em si mesmos como inteiros quando eles são confrontados pela alteridade que a imagem apresenta a eles". Aqui, retomamos famosas discussões nessa área sobre as maneiras como as fotografias relacionam-se com as memórias, seja através do despertar de lembranças ou ao funcionar como comprovação física e simbólica de momentos, além das dualidades na construção social e pessoal das fotografias.

Essas tendências são particularmente observáveis em duas obras referenciais na trajetória de Sophie Calle: Douleur Exquise (2003) e Prenez Soin de Vous (2007). Ambas tratam de experiências da francesa frente a términos de relacionamentos; contudo, conforme assinala Hupe (2010, p. 194), “a artista trabalha acontecimentos pessoais tentando universalizá-los; sua trajetória demonstra empenho em impessoalizar o eu". Mesmo quando desenvolve projetos que colocam o outro à luz da investigação, Sophie Calle tenta trabalhar o sentimento de maneira coletiva, numa transferência para o mundo externo, generalizando e espetacularizando a experiência. Isso só é possível devido à combinação que ela realiza entre texto, imagem e elementos gráficos, bem como a maneira como eles são organizados e ressignificados.

Douleur Exquise, por exemplo, embora dividido em dois atos, reúne diversos formatos narrativos. O projeto é resultado da superação tardia de um luto - em 1984, Calle realizou uma viagem de três meses ao Japão e, ao final, viu-se diante de um término de relacionamento. Ao retornar à França três dias depois, ela passa a relatar a situação a seus amigos e desconhecidos e, para superar a dor, lhes perguntava: "quando você mais sofreu?". A recuperação pessoal se deu em três meses (CALLE, 2003), mas foi somente quinze anos mais tarde que a autora tomou coragem para se debruçar sobre suas fotografias e memórias para construir o trabalho.

Na primeira parte, entitulada “Antes da Dor”, Calle relata suas experiências durante sua viagem ao Japão utilizando textos e fotografias. Eles são organizados numa espécie de diário, com marcações gráficas semelhantes a um carimbo para contar os dias; contudo, grande parte do conteúdo textual é endereçado a "mon amour" (meu amor, em português), o que também remete à troca de correspondências. Este segmento, repleto de discursos ambíguos e desconfianças, se encerra com uma grande fotografia do quarto de hotel onde a autora recebeu a notícia do rompimento. Aqui, há grande semelhança com o caráter performático da obra Suite Venetienne: é difícil atestar a veracidade do relato de Calle, já que ele foi efetivado anos depois da experiência e pode ter sido facilmente manipulado para provar o seu ponto de vista. 
Em seguida, inicia-se a segunda parte da obra, "Depois da Dor", na qual Calle inclui os relatos de dor de seus entrevistados. Eles aparecem em discurso direto e são sempre acompanhados de uma fotografia aparentemente banal, mas relacionada ao texto. Em todos os suportes da obra, esses relatos são apresentados ao lado direito; no lado esquerdo, Calle inclui todas as vezes a fotografia do quarto de hotel, acompanhada de seu próprio relato sobre o episódio do rompimento. Estes relatos são sempre reescritos de maneira diferente e, aos poucos, vão se esvaindo graficamente - a tipografia vai perdendo cor, até que, na última página, desaparece completamente; a obra e o luto, enfim, concluídos.

Já Prenez Soin de Vous segue uma abordagem diferente. No dia 24 de Abril de 2004, Sophie Calle recebeu um e-mail de G. atestando o término de seu relacionamento. Diante da incapacidade de respondê-lo, a autora decide seguir o conselho que seu interlocutor lhe dá ao final do documento: "prenez soin de vous" (em português, "cuidese"). Envolve-se, então, em um projeto pessoal no qual pede a 107 mulheres, escolhidas por sua profissão ou habilidades, para interpretar a carta por ela: "analisá-la, comentá-la, dançá-la, cantá-la, dissecá-la, exauri-la, entendê-la por ela, respondê-la por ela” (2007, sem página). Calle justifica a medida como uma maneira de levar seu próprio tempo para o rompimento.

O trabalho finalizado recebeu, então, o nome de Prenez Soin de Vous e foi inicialmente apresentado como uma exposição do pavilhão francês da $52^{\mathrm{a}}$ Bienal de Veneza, em 2007. O projeto foi muito bem recebido pela crítica e, em 2010, a artista foi contemplada com o Hasselblad Award, um dos mais relevantes prêmios internacionais em fotografia, pelo conjunto de sua obra. Calle afirma que foi em Prenez Soin de Vous que a fotografia assumiu novas dimensões de identificação para ela: "ao confiar o texto aos outros, eu o perdi de alguma forma. Eu tive que achar o MEU lugar. E então eu voltei para a imagem, e foi nesse ponto que ela se tornou prioridade" (CALLE, 2011).

Enquanto as análises textuais das 107 mulheres flutuam entre opiniões e pontos de vista, as fotografias são diretas em sua função: identificam e personificam as convidadas, comprovam os encontros e, sobretudo, relembram o leitor da presença quase invisível de Calle ao longo do processo. Trata-se de um jogo muito complexo de interpretação - em ambos os sentidos da palavra, de processo e de resultado -, no qual a fotografia desempenha um papel unificador. Há um diálogo muito interessante entre os diversos 
personagens dentro da obra, e essa multiplicidade é ressaltada pela variedade de elementos gráficos e discursivos que a compõem.

\section{Considerações Finais}

Um dos grandes enigmas nas obras de Calle é compreender as relações que ela estabelece entre o real e o ficcional. Apesar de tratar de temas muito subjetivos e sentimentais - como o amor, a ausência, a beleza, a morte e desejos pessoais - a autora se utiliza de elementos, a priori, documentais - como a fotografia, entrevistas, investigações e transcrições de cartas e diários - para conectar e estruturar suas narrativas. Sabe-se que Sophie Calle comunica memórias, mas é difícil distinguir de quem são essas lembranças, já que os discursos pessoal e alheio se fundem num diálogo subjetivo e dependente do outro para existir. As histórias que conta são constantemente ressignificadas através dos detalhes, de novas interpretações e (por que não) através de relações construídas com as memórias dos próprios leitores e espectadores.

Dessa forma, pode-se dizer que o trabalho de Calle nos leva a um debate muito mais amplo sobre a forma como comunicamos memórias e sobre a importância dos elementos que utilizamos para representá-las. A autora não se preocupa exclusivamente com o ato fotográfico ou verbal, mas com a idéia (ou ausência dela) que essa combinação transmite. Trata-se de um processo em constante construção, no qual a relação específica entre referente externo e a mensagem produzida modifica-se por fatores culturais, sociais, técnicos, sociológicos, estéticos e muitos outros.

Conforme explica Dubois (1994, p. 40), "a caixa preta fotográfica não é um agente reprodutor neutro, mas uma máquina de efeitos deliberados, ao mesmo modo que a língua é um problema de convenção e instrumento de análise e interpretação do real". Essa codificação assemelha-se muito ao processo de conceptualização e categorização das palavras: apesar de memorizarmos nossas impressões sensíveis e as registrarmos fisiologicamente, seus conceitos são dinâmicos (BIDERMAN, 1998). Através dessas mudanças, palavra e fotografia assumem um papel importante de mediação da realidade e também das memórias.

É muito interessante notar a maneira como Calle articula esses elementos. Inserida num contexto de produção artística marcado pela relativização, a artista usa de maneira 
sagaz as possibilidades oferecidas pela combinação de texto e imagem, ao mesmo tempo em que promove a discussão de dualidades paradoxais na conjuntura social atual: verdade e ficção, público e privado, identificação e distância, vulnerabilidade e aproximação. Ao gratificá-la com o Hasselblad Award, o comitê julgador apontou: "[seu trabalho] evoca narrativa, afeição e emoção de maneiras que ao mesmo tempo comovem profundamente o espectador e fazem-no refletir sobre os potenciais e os limites da fotografia". Sua contribuição prática e cativante inspirou centenas de artistas e teóricos, e suas controvérsias merecem atenção justamente porque possibilitam uma infinidade de novas interpretações.

\section{Referências Bibliográficas}

BIDERMAN, M.T.C. Dimensões da Palavra. Filologia e Linguística Portuguesa. n. 2, p.81-118, 1998.

CALLE, S. Sophie Calle: 'I asked for the moon and I got it'. The Guardian. Janeiro de 2011. Disponível em: <http://www.theguardian.com/artanddesign/2011/jan/09/sophiecalle>, acesso em: 25 de Novembro de 2014.

CALLE, Sophie. Prenez soin de vous. Paris: Actes Sud, 2007.

CALLE, Sophie. Douleur exquise. Paris: Actes Sud, 2003.

CALLE, Sophie. Doubles-Jeux. Paris: Actes Sud, 1998.

DUBOIS, P. O ato fotográfico e outros ensaios. Campinas: Papirus, 1994. 362 p.

EDWARDS, N.; HUBBELL, A. L.; MILLER, A. Introduction: Textual and Visual Selves. In: EDWARDS, N.; HUBBELL, A. L.; MILLER, A. (Org.). Textual and Visual Selves: Photography, Film and Comic Art in French Autobiography. Lincoln: University of Nebraska Press, 2011.p. 01-28. 
GRATTON, J. Illustration Revisited: Phototextual Exchange and Resistance in Sophie Calle's Suite Venetienne. In: EDWARDS, N.; HUBBELL, A. L.; MILLER, A. (Org.). Textual and Visual Selves: Photography, Film and Comic Art in French Autobiography. Lincoln: University of Nebraska Press, 2011. p. 139-166.

HASSELBLAD FOUNDATION. Sophie Calle - 2010 Hasselblad Award Winner. Hasselblad Foundation. Março de 2010. Disponível em:

<http://www.hasselbladfoundation.org/assets/downloads/haw2010/presslongeng.pdf>, acesso em: 25 de Novembro de 2014.

HUPE, Ana. As mulheres de Sophie Calle. Revista Concinnitas. Ano 11, vol. 1, n. 16. p. 192-197, jun 2010.

JORDAN, S. Chronicles of Intimacy: Photography in Autobiographical Projects. In: EDWARDS, N.; HUBBELL, A. L.; MILlER, A. (Org.). Textual and Visual Selves: Photography, Film and Comic Art in French Autobiography. Lincoln: University of Nebraska Press, 2011. p. 51-78.

LE GOFF, J. História e Memória. Campinas: Ed. da Unicamp, 1996. 553p.

MONTÉMONT, V. Beyond Autobiography. In: EDWARDS, N.; HUBBELL, A. L.; MILLER, A. (Org.). Textual and Visual Selves: Photography, Film and Comic Art in French Autobiography. Lincoln: University of Nebraska Press, 2011. p. 29-50.

O'NEILL BUTLER, L. The Savage Detective: On Sophie Calle's 'Address Book'. Los Angeles Review of Books. Outubro de 2012. Disponível em:

<https://lareviewofbooks.org/review/the-savage-detective-on-sophie-calles-address-book>, acesso em: 25 de Novembro de 2014.

POLLAK, M. Memória e Identidade Social. In: Estudos Históricos. Rio de Janeiro. vol. 5, n. 10, p. 200-212, 1992. 